\title{
Meat intake and bladder cancer in a prospective study: a role for heterocyclic aromatic amines?
}

\author{
B. Lumbreras $\cdot$ S. Garte $\cdot$ K. Overvad $\cdot$ A. Tjonneland $\cdot$ F. Clavel-Chapelon $\cdot$ J. P. Linseisen $\cdot$ \\ H. Boeing $\cdot$ A. Trichopoulou $\cdot$ D. Palli $\cdot$ M. Peluso $\cdot$ V. Krogh $\cdot$ R. Tumino $\cdot$ S. Panico \\ H. B. Bueno-De-Mesquita $\cdot$ P. H. Peeters $\cdot$ E. Lund $\cdot$ C. Martinez $\cdot$ M. Dorronsoro $\cdot$ \\ A. Barricarte · M. D. Chirlaque · J. R. Quiros · G. Berglund · G. Hallmans · N. E. Day · \\ T. J. Key · R. Saracci $\cdot$ R. Kaaks $\cdot$ C. Malaveille $\cdot$ P. Ferrari $\cdot$ P. Boffetta $\cdot$ T. Norat $\cdot$ \\ E. Riboli $\cdot$ C. A. Gonzalez $\cdot$ P. Vineis
}

Published online: 26 April 2008

(C) Springer Science+Business Media B.V. 2008

\section{Erratum to: Cancer Causes Control \\ DOI 10.1007/s10552-008-9121-1}

An incorrect list of affiliations was published. The current and correct list attached.

The online version of the original article can be found under doi:10.1007/s10552-008-9121-1.

\author{
B. Lumbreras \\ Imperial College London, London, UK \\ B. Lumbreras \\ Department of Public Health, University Miguel Hernandez, \\ Alicante, Spain \\ B. Lumbreras \\ CIBER en Epidemiología y Salud Pública (CIBERESP), \\ Barcelona, Spain \\ S. Garte \\ Genetics Research Institute, Milano, Italy \\ K. Overvad \\ Department of Epidemiology and Social Medicine, \\ University of Aarhus, Aarhus, Denmark \\ A. Tjonneland \\ Institute of Cancer Epidemiology, Danish Cancer Society, \\ Copenhagen, Denmark \\ F. Clavel-Chapelon \\ INSERM (Institut National de la Santé et de la Recherche \\ Médicale), Institut Gustave Roussy, Villejuif, France \\ J. P. Linseisen \\ Division of Clinical Epidemiology, Deutsches \\ Krebsforschungszentrum, Heidelberg, Germany
}

H. Boeing

German Institute of Human Nutrition, Potsdam-Rehbucke,

Germany

A. Trichopoulou

Department of Hygiene and Epidemiology, Medical School,

University of Athens, Athens, Greece

D. Palli

Molecular and Nutritional Epidemiology Unit,

CSPO-Scientific Institute of Tuscany Region,

Florence, Italy

\section{Peluso}

Cancer Risk Factor Branch, Analytical and Biomolecular Cytology Unit, CSPO-Scientific Institute of Tuscany, Florence, Italy

V. Krogh

Department of Epidemiology, National Cancer Institute,

Milan, Italy

R. Tumino

Cancer Registry, Azienda Ospedaliera 'Civile MP Arezzo', Ragusa, Italy

\section{S. Panico}

Dipartimento di Medicina Clinica e Sperimentale, Università Federico II, Naples, Italy 
H. B. Bueno-De-Mesquita

Centre for Nutrition and Health, National Institute for Public Health and the Environment, Bilthoven, The Netherlands

\section{P. H. Peeters}

Julius Center for Health Sciences and Primary Care,

University Medical Center, Utrecht, The Netherlands

\section{E. Lund}

Institute of Community Medicine, University of Tromso,

Tromso, Norway

\section{Martinez}

Andalusian School of Public Health, Granada, Spain

M. Dorronsoro

Department of Public Health of Guipuzkoa, San Sebastian, Spain

\section{A. Barricarte}

Public Health Institute, Navarra, Spain

\section{D. Chirlaque}

Epidemiology Department, Murcia Health Council and CIBER en Epidemiología y Salud Pública (CIBERESP), Murcia, Spain

\section{J. R. Quiros}

Public Health and Health Planning Directorate, Asturias, Spain

G. Berglund

Malmö Diet and Cancer Study, Lund University, Malmo,

Sweden
G. Hallmans

Nutritional Research, Umeå University Hospital,

Umea, Sweden

N. E. Day

MRC Dunn Human Nutrition Unit, Cambridge University,

Cambridge, UK

T. J. Key

Cancer Research UK Epidemiology Unit, University of Oxford, Oxford, UK

R. Saracci

IFC National Research Council, Pisa, Italy

R. Kaaks

Division of Epidemiology, DKFZ, Heidelberg,

Germany

C. Malaveille · P. Ferrari · P. Boffetta

International Agency for Research on Cancer, Lyon, France

T. Norat · E. Riboli $\cdot$ P. Vineis $(\square)$

Department of Epidemiology and Public Health,

Imperial College of Science, Technology and Medicine,

Norfolk Place, W2 1PG London, UK

e-mail: paolo.vineis@unito.it

C. A. Gonzalez

Department of Epidemiology, Catalan Institute of Oncology,

Barcelona, Spain 